\title{
Development of automation system of the process of electromagnetic treatment of industrial wastewater from ferromagnetic impurities
}

https://doi.org/10.31713/MCIT.2020.16

Andrii Safonyk

National University of Water and Environmental Engineering Institute of Automatics, Cybernetics and Computer

Engineering

Rivne, Ukraine

a.p.safonyk@nuwm.edu.ua

Ivanna Hrytsiuk

National University of Water and Environmental Engineering Institute of Automatics, Cybernetics and Computer

Engineering

Rivne, Ukraine

i.m.hrytsiuk@nuwm.edu.ua

\author{
Anna Burduk \\ Wroclaw University of Technology, \\ Wroclaw, Poland \\ anna.burduk@pwr.edu.pl
}

\begin{abstract}
A mathematical model of the iron removal process taking into account the factors influencing the quality of cleaning was presented. Based on the mathematical model, a control algorithm was developed, which became the basis of the structural control scheme. Further, was set up the graphical screen for automatic and manual control, display errors and main parameters of information technology projects.
\end{abstract}

Keywords-mathematical modelling, ferromagnetic impurities, transfer functions, water treatment technology

\section{INTRODUCTION}

Wastewater treatment has been the main focus of many scientists for many years. The method of magnetic water purification has a number of advantages, which makes it advanced and therefore used around the world. In the theory of filtration processes, there are a number of important problems that need to be solved, in particular: development of universal mathematical models that describe the technological processes of wastewater treatment in general with variable system parameters; taking into account the factors that have a significant impact on the quality of treatment by making the appropriate coefficients in the dependencies; development of automated control systems for filtering processes. Considering the work in this area, we conclude that there are almost no dedicated to the development of algorithms for automated control of the technological processes of wastewater treatment. Therefore, we aim to develop a system for automating the process of iron removal of industrial waters on the basis of the developed universal mathematical model that takes into account the variable parameters of the system and the factors that affect the quality of treatment $[2,4]$.
Vasyl Pasichnyk

National University of Water and Environmental Engineering Institute of Automatics, Cybernetics and Computer

Engineering

Rivne, Ukraine

v.a.pasichnyk@nuwm.edu.ua

\section{MATHEMATICAL MODEL OF THE DEIRONING PROCESS}

The process of water purification in a magnetic filter is described by differential equations of partial derivatives [1-3]. Therefore, we use the model developed in [5]:

$$
\begin{gathered}
\left\{\begin{array}{c}
\frac{\partial(\sigma(\rho) c(x, t))}{\partial t}+\frac{\partial \rho(x, t)}{\partial t}+\frac{\partial v c(x, t)}{\partial x}=0, \\
\frac{\partial \rho(x, t)}{\partial t}=\beta(H, v, d) c(x, t)-\varepsilon \alpha(\rho) \rho(x, t),
\end{array}\right. \\
\left.c\right|_{x=0}=c_{*}^{*}(t),\left.c\right|_{t=0}=0,\left.\rho\right|_{x=0}=0,\left.\rho\right|_{t=0}=0, \\
v=\kappa(\rho) \cdot \operatorname{grad} p,
\end{gathered}
$$

where $c(x, t)$ the concentration of impurities in the filtered liquid medium; $\rho(x, t)$ - concentration of impurities precipitated in the granular filter material; $\beta$ - coefficient characterizing the mass volumes of deposition of impurity particles per unit time $\beta(H, v, d)=\frac{\beta_{0} H^{0.75}}{v d^{2}}$ [1], where $\beta_{0}-$ free parameter, $H$ - magnetic field strength (proportional to the applied current), $v$ - filtration rate, $d$ - diameter of the granules of the filter material), $\alpha(\rho, H)$ - coefficient characterizing the mass volumes of impurity particles detached at the same time from the granules of the filter material;

$$
\alpha(\rho)=\alpha_{0}+\varepsilon \alpha_{*} \rho(x, t),
$$


$c_{*}^{*}(t)$ - the concentration of impurity particles at the inlet of the filter, $\sigma(\rho)$ - the porosity of the filter material $\left(\sigma_{0}-\right.$ the original porosity of the filter material),

$$
\sigma(\rho)=\sigma_{0}-\varepsilon \sigma_{*} \rho(x, t),
$$

$\kappa(\rho)$ - filtration coefficient, $\rho_{0}=\rho\left(L, \tau_{3}\right)$,

$$
\kappa(\rho)=\left[\begin{array}{l}
\kappa_{0}-\varepsilon \gamma \rho(x, t), \rho<\rho_{0}, \\
\kappa_{0}-\varepsilon \gamma \rho\left(x, \tau_{3}\right), \rho \geq \rho_{0},
\end{array}\right.
$$

$\alpha_{0}, \alpha_{*}, \sigma_{*}, \kappa_{0}, \gamma, \varepsilon$ - rigid parameters (they characterize the corresponding coefficients) $\alpha(\rho), \sigma(\rho), \kappa(\rho)$ - variable parameters (found experimentally), $\varepsilon-$ small parameter, $p-$ pressure. Note that, in contrast to [1-3], in a more general case, the pressure $p=p(x, t)$ would be rational to determine as a result of solving the equation $\frac{\partial}{\partial x}\left(\kappa(\rho) \frac{\partial p}{\partial x}\right)=\frac{\partial \sigma(\rho) p}{\partial t}$, which is obtained on the basis of the above equation of motion and the equation of state: $\operatorname{div} v=\frac{\partial \sigma(\rho) p}{\partial t}$ ) at the edge $p(0, t)=p_{*}(t), \quad p(L, t)=p^{*}(t) \quad(0<t<\infty)$ and initial $p(x, 0)=p_{*}^{*}(x), 0<x<L$ conditions $p_{*}(t), p^{*}(t), p_{*}^{*}(x)-$ are given rather smooth and coordinated in angular points of area of $G=\{(x, t): 0<x<L, 0<t<\infty\}$ function. Thus, in the course of the decision of a problem, we can define the corresponding $\operatorname{grad} p$, value, in particular - a pressure difference $\Delta P=p^{*}(t)-p_{*}(t)$ on an entrance and an exit from the filter.

The results of the computer experiment are shown in Figure 1-Figure 4.

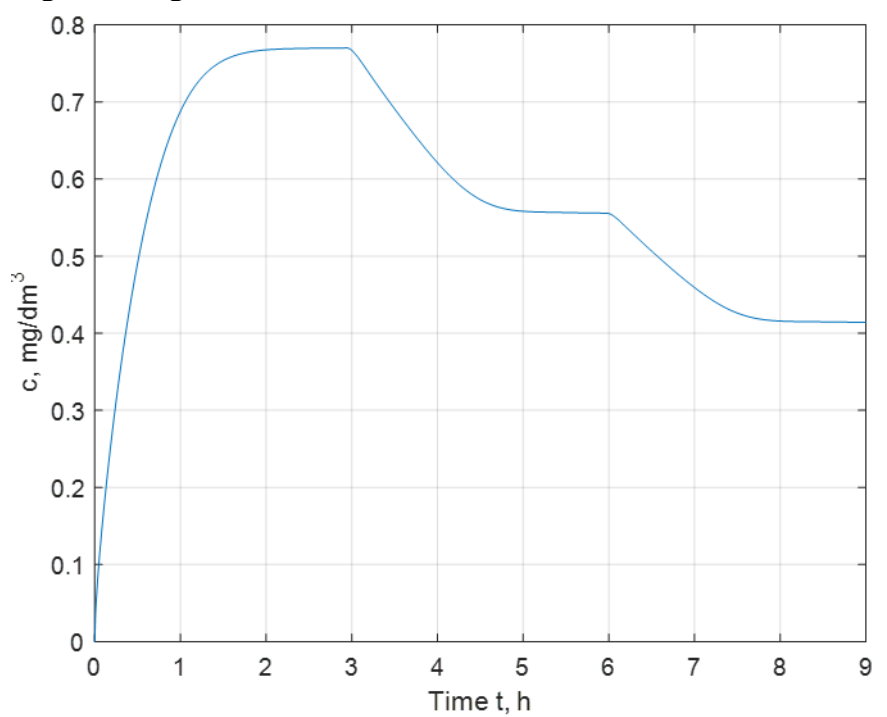

Figure 1. Dynamics of change of work of installation on current gradually increases

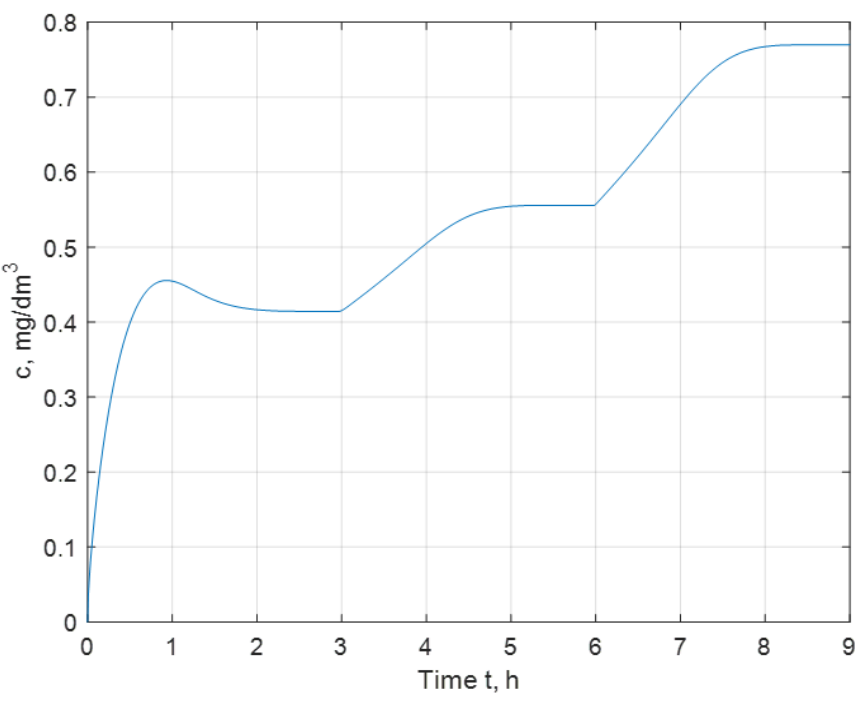

Figure 2. Dynamics of change of work of installation on current gradually decreases

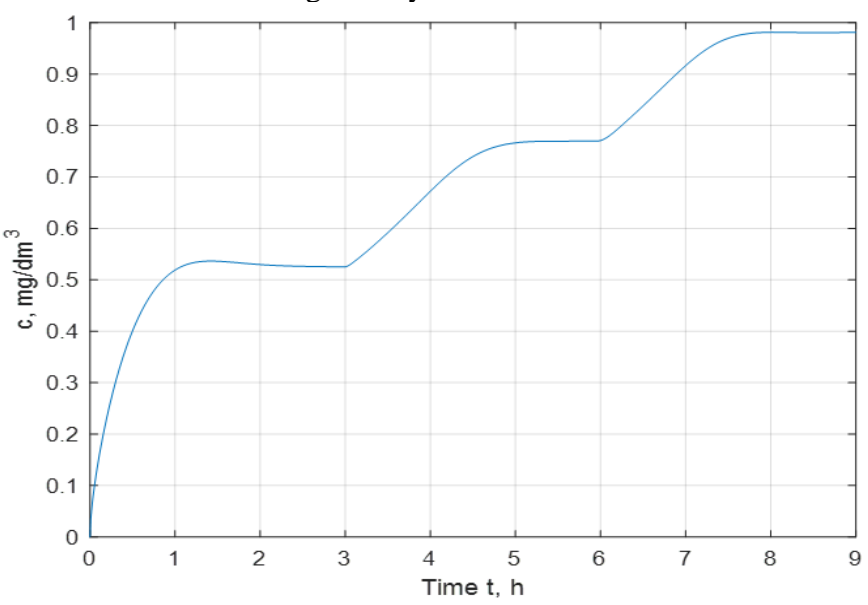

Figure 3. Dynamics of change of work of installation on a expense gradually increases

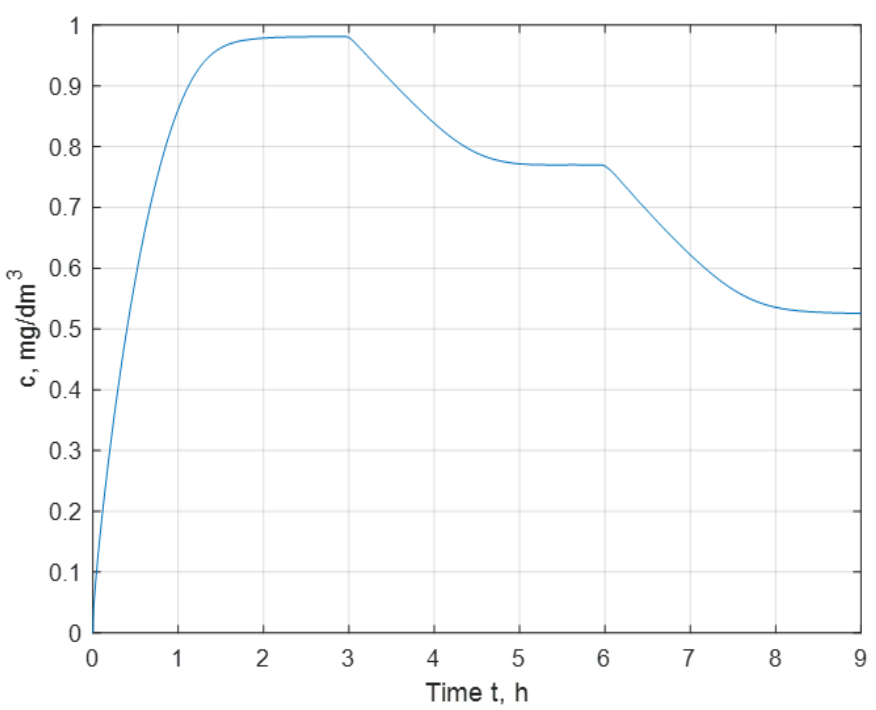

Figure 4. Dynamics of change of work of installation on a expense gradually decreases 


\section{DEVELOPMENT OF CONTROL ALGORITHM AND AUTOMATION SYSTEM}

The following factors were taken into account when developing the system control algorithm:

- the magnetic purification system must provide a given concentration of iron-containing impurities at the outlet at different flow rates of process water;

- the input concentration of pollution is a variable parameter and in accordance with the number of ironcontaining impurities, the magnetic field strength is regulated;

- the magnetic field strength must be maintained at a given level with the control of the current in the power supply circuit;

- the regulator must maintain the magnetic field strength in proportion to the level of contamination of process water to provide minimal electricity consumption while maintaining the quality of treated water.

Given the above, a block diagram of the proposed algorithm was developed, which is presented in Fig. 5

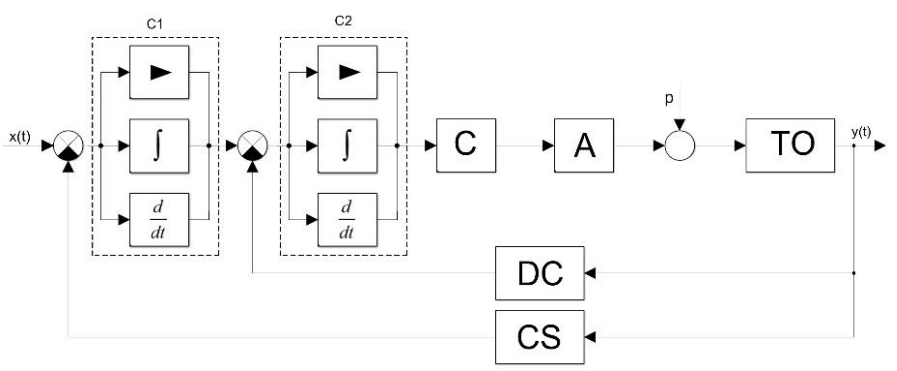

Figure 5. Block diagram of the algorithm for controlling the

allowable concentration of impurities in wastewater: $C 1$ - standard PI

- regulator for calculating the magnetic field strength applied to the

electromagnet; $C 2$ - system PID - regulator to maintain a given

current at the appropriate level when compared with the actual

current flowing in the power supply circuit of the magnetic filter; $C$ -

regulating body, which in this system is the controller that controls

the magnitude of the applied voltage from the amplifier to the

electromagnet; $A$ - actuator (amplifier), which supplies voltage to the electromagnet; $T O$ - technological object, which is a magnetic filter;

$D C$ - current sensor that measures the real current flowing in the

power supply circuit of the electromagnet; $C S$ - sensor of

concentration of iron-containing impurities at the entrance to the

magnetic filter, which shows the change of input concentration to

implement the control mode; $p$ - perturbation.

According to the block diagram, the system will work as follows: setting the permissible concentration of pollution is compared with the value of the input concentration (CS) and if the system receives contamination with a concentration exceeding the established permissible norms, the automation system is started.

The first step is to represent the value of the input concentration of pollution on a standard PI - regulator (C1), which according to the dependence calculates the value of the magnetic field strength to be applied to the electromagnetic to generate sufficient force in the magnetic filter to overcome the way at a given flow rate. The concentration of contamination of the target component at the outlet of the treatment plant. The obtained value is compared with the magnitude of the current flowing in the power supply circuit of the magnetic filter at the moment. The obtained difference is given to a standard PID - regulator (C2), which converts the input current signal into a unified voltage $0 \ldots 5 \mathrm{~V}$, which is controlled the amplifier. All the described actions take place in the controller by exchanging signals with visualization, sensors and processing of the control program in accordance with the obtained results.

The next step is to transmit control signals from the analog output of the controller (C) to the actuator (A), which is connected to the $220 \mathrm{~V}$ AC power supply and produces a $24 \mathrm{~V}$ DC signal of high currents. The analog signal from the controller is fed to the analog input of the amplifier, which produces a proportional signal at the output of +24 VDC, fed to the power supply circuit of the electromagnet. At this voltage in the magnetic filter there is a sufficient magnetic field to retain a given concentration of iron-containing impurities, which are fed directly into the magnetic cleaning system (TO).

A (DC) sensor is used to maintain the current at a given level.

For hardware implementation of this project the programmable logic controller S-7 300 of the Siemens enterprise with expansion modules is used. Using Simatic Step7 Manager, a process control program was written, preconfiguring the controller hardware and creating a symbol table, which describes all the inputs, outputs, labels with their symbolic, hardware names and comments. The main components of the program are the implementation of the method of determining and maintaining the required current in the power supply circuit of the electromagnet. To perform this task, a standard PID controller is used, which performs the function of regulating the current in accordance with the task of magnetic field strength. A functional unit has also been developed that calculates the required current for effective retention of iron-containing impurities at variable concentrations of incoming pollution. The input parameters of this unit include the concentration of pollution in process waters and empirical coefficients, which are calculated by modeling the system in Matlab.

All functions of regulation and control of the main 
parameters in the designed automation system are performed by the programmable logic controller S-7 300 of the Siemens enterprise with modules of expansion of discrete inputs SM321, analog inputs SM331 and discrete outputs SM322, which at this configuration has four analog inputs, sixteen discrete inputs. and sixteen discrete outputs, which are sufficient to control this system. The CP343 communication module is used to connect the controller to the operator's PC and the network of controllers.

This system will have 2 control loops that provide the following technological parameters at the appropriate level:

1. Concentration of contamination in a liquid environment.

2. Process water pressure at the outlet of the system.

Also controls the following technological parameters:

1. The pressure of contaminated water at the inlet of the filter 1 .

2. The pressure of contaminated water at the inlet of the filter 2 .

In order to detect deviations in the technological process and in case of deviation of critical parameters to make an emergency stop of the technological process by blocking the supply of contaminated water to the system by a shut-off valve.

A graphical part of the control system project is developed to represent the workflow in the Scada system using a view editor. All forms of information display, control and animation effects are linked to the information structure developed in Simatic Step7.

For the implementation of the project, a graphical screen (Fig. 6) was created on which automatic and manual control of the process, display of errors in the operation of the respective devices, as well as display of the main informative parameters of the technological process, such as: the direction of fluid flow by the green indicator of the corresponding parts of the valves, pump filters, as well as water flow data and pressure drops in the magnetic filter system.

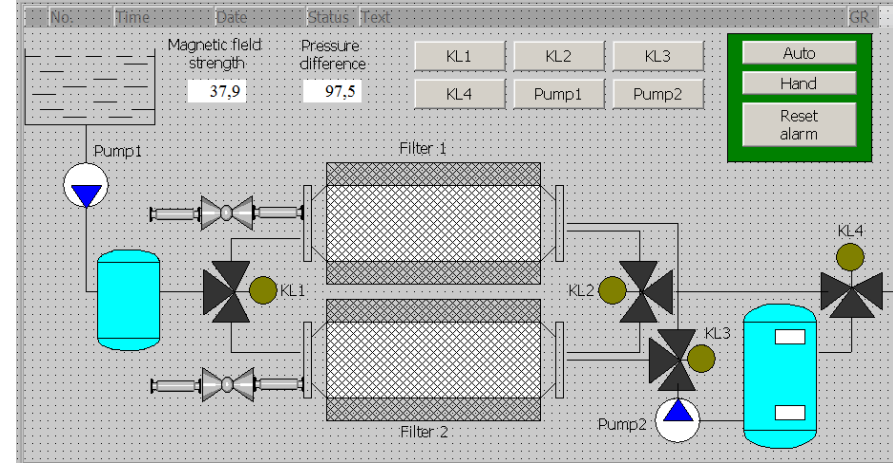

Figure 6. Graphic window to display the progress of the technological process

\section{CONCLUSION}

Based on the mathematical model of the iron removal process, a block diagram of the algorithm for controlling the concentration of impurities in industrial waters, which provides for regulating the magnetic field strength applied to the electromagnet and maintaining a given current at the appropriate level was built. Automatic and manual process control, display of errors in work of the corresponding devices, and also display of the main informative parameters of technological process in real time with the use of SCADA - WinCC Flexible system is provided.

\section{REFERENCES}

[1] A.P. Safonyk I.M. Tarhonii V.A. Pasichnyk. Matematychnyi Analiz Parametriv I Modeli Protsesu Mahnitnoho Osadzhennia Domishok. Visnyk Inzhenernoi Akademii Ukrainy 1, 2018, S. 105-110.

[2] Andrey Ya. Bomba, Andrey P. Safonyk, Elena A. Fursachik. Identification of Mass Transfer Distribution Factor and Its Account for Magnetic Filtration Process Modeling. Journal of Automation and Information Sciences, Volume 45, Issue 4, 2013, pp. 16-22.

[3] A.P. Safonyk. Kompiuterne Modeliuvannia Ta Avtomatyzatsiia Protsesu Filtruvannia Ta Reheneratsii V Mahnitnomu Filtri. Visnyk Inzhenernoi Akademii Ukrainy 1, 2015, S. 202-208.

[4] A. Safonyk. Modelling and automation of process of water purification by magnetic filter. Informatyka Automatyka Pomiary w Gospodarce i Ochronie Środowiska 1/2016, Poland, 2016, pp. 32-36.

[5] A.P. Safonyk I.M. Tarhonii. Kompiuterne Modeliuvannia Ta Avtomatyzatsiia Protsesu Mahnitnoho Ochyshchennia Vody. Byonyka Yntellekta Nauch.-Tekhn. Zhurnal, №2(83), 2014, s. 117-122. 